\title{
NADH-Cytochrome $b_{5}$ Reductase Activity in Lymphoid Cell Lines
}

\author{
EXPRESSION OF THE DEFECT IN EPSTEIN-BARR VIRUS TRANSFORMED \\ LYMPHOBLASTOID CELL LINES FROM PATIENTS \\ WITH RECESSIVE CONGENITAL METHEMOGLOBINEMIA
}

\author{
Danielle Lostanlen, Gilbert Lenoir, and Jean-Claude Kaplan, Institut \\ de Pathologie Moléculaire, Institut National de la Sante et de la Recherche \\ Médicale U 129, 75674 Paris Cedex 14; International Agency for \\ Research on Cancer, 69372 Lyon Cedex 02 France
}

A B S T RA C T Recessive congenital methemoglobinemia (RCM) is due to the homozygous deficiency of NADH-cytochrome $b_{5}$ reductase (EC 1.6.2.2.). In type I disease, in which the patients are only methemoglobinemic, the enzyme defect is fully expressed in the erythrocytes, whereas the leukocytes are much less affected. In type II disease, in which the patients are, in addition, mentally retarded, the defect is generalized to all the tissues including cultured fibroblasts. In the present study we have investigated Epstein-Barr virus (EBV) transformed lymphoid cell lines (LCL) derived from patients with both types of cytochrome $b_{5}$ reductase deficiency and from nondeficient individuals. The total cytochrome $b_{5}$ reductase activity of the control LCL was found to be similar whatever the LCL origin, except for one lymphoma line (Daudi). The enzyme from the control LCL (C 252/B 95) was found to be immunologically related to the human soluble erythrocyte cytochrome $b_{5}$ reductase, indicating that it is the product of the same gene: the DI $A_{1}$ (diaphorase) locus. The LCL derived from one patient with the type I disease and two patients with the type II disease were investigated. In the former the defect was expressed to a lesser degree than in the cases with mental retardation in which the defect was much pronounced, and involved both the mitochondrial and the microsomal fractions. This indicates that all the subcellular forms of the cytochrome $b_{5}$ reductase are under the same genetic control. Altogether, these data show that the LCL are a favorable material for studying both types of cytochrome $b_{5}$ reductase deficiency and for in-

Received for publication 28 November 1980 and in revised form 18 February 1981. vestigating in depth the molecular aspects of this metabolic disease.

\section{INTRODUCTION}

Recessive congenital methemoglobinemia (RCM) ${ }^{1}$ is due to the homozygous deficiency of erythrocyte NADH-diaphorase (1). This enzyme was found to be ubiquitously distributed (2) and to represent a soluble form of cytochrome $b_{5}$ reductase (3). The identity between the microsomal form of cytochrome $b_{5}$ reductase and the erythrocyte soluble form so-called "methemoglobin reductase," was assessed by immunological methods (4-6). Two clinical forms of RCM have been defined (7): ( $a$ ) a benign form, called type $I$ in which the erythrocytes are mainly affected, whereas the leukocytes are normal or much less affected; $(b)$ a severe form with mental retardation, called type II, in which the enzyme defect is generalized to all the tissues: liver, muscle, brain, leukocytes, fibroblasts $(7,8)$. These two different forms are probably due to different mutations at the same locus DIA, which has been assigned to chromosome $22(9,10)$. To further understand the molecular pathology of cytochrome $b_{5}$ reductase deficiency, continuous lymphoblastoid cell lines (LCL) were established by Epstein-Barr virus (EBV) infection of peripheral lymphocytes from one patient with type I RCM, and two patients with type II RCM. The aim of this work was to study the molecular forms of cytochrome $b_{5}$ reductase in control

\footnotetext{
${ }^{1}$ Abbreviations used in this paper: EBV, Epstein-Barr virus; LCL, lymphoid cell lines; RCM, recessive congenital methemoglobinemia.
} 
lymphoblastoid cell lines, and to see if the mutations affecting the DIA 1 gene were expressed in EBV transformed LCL in both forms of disease.

\section{METHODS}

\section{LCL and culture conditions}

Three types of control LCL were investigated: (a) LCL established by in vitro EBV infection (11) of normal cord blood human lymphocytes isolated on Ficoll-Hypaque (Radiopaque Media, Winthrop Laboratories, New York). Six different lines, designated C 252/B 95, C 18/M 81, C 18/B 95, C 34/ M 81, C 62/M 81, C 62/B 95 were studied. (b) Lymphoblastoid cell lines spontaneously obtained from patients with nasopharyngeal carcinoma. These cell lines, containing the EBV genome (Ly 11, Ly 26, Ly 28, Ly 64, and Ly 72) had been established by cultivation of nasopharyngeal carcinoma tumor as reported before (12). (c) Lymphoma cell lines from Burkitt's tumors: two of them containing the EBV genome (RAJI and DAUDI) the third one (BJAB) being free of EBV DNA.

Cytochrome $b_{5}$ reductase deficient lines were established by EBV infection of peripheral blood lymphocytes (11) from one subject with type I disease (without mental retardation): line REN, and from two subjects with type II disease (with mental retardation): lines BEN and BOU. Preliminary reports of the case study of these three patients have been published (7).

In all cases, the cells were cultivated in RPMI 1640 containing $20 \%$ heat-inactivated fetal calf serum, $100 \mathrm{IU} / \mathrm{ml}$ of penicillin and $100 \mu \mathrm{g} / \mathrm{ml}$ streptomycin. The cells were collected $3 \mathrm{~d}$ after medium change and were still at this moment in exponential growth phase. In one experiment, cells were collected 1,3 , or 7 days after medium change. The cells collected after $7 \mathrm{~d}$ had already reached saturation density 2 or $3 \mathrm{~d}$ before. The cell suspensions were washed twice in phosphate buffered saline, and stored at $-70^{\circ} \mathrm{C}$ as frozen pellets until enzyme analysis.

\section{Leukocyte and fibroblast preparations of normal and cytochrome $b_{5}$ reductase deficient patients}

Leukocytes were obtained by sedimentation of whole blood added to polyvinyl pyrrolidone $(4: 1 \mathrm{vol})$ for $1 \mathrm{~h}$ at $37^{\circ} \mathrm{C}$; the contaminating erythrocytes were removed by osmotic shock. Skin fibroblasts were cultivated in Eagle's minimal essential medium containing $10 \%$ calf serum. The pellets of leukocytes and fibroblasts were stored at $-70^{\circ} \mathrm{C}$ immediately after centrifugation.

\section{Preparation of detergent-treated cell extracts}

Procedure 1: total extracts. The cell pellet (containing $\sim 10^{8}$ cells) was suspended in $0.3 \mathrm{ml}$ of $1 \%$ (wt/vol) Triton X-100 (Sigma Chemical Co., St. Louis, Mo.) in water, vigorously stirred in a Vortex apparatus, and frozen and thawed three times. The $12,000 \mathrm{~g}$ supernate was used for enzyme assays and characterization.

Procedure 2: cell fractionation. The cell pellet $\left(10^{8}\right.$ cells) was homogenized with a Teflon Potter homogenizer in 3 vol of $0.25 \mathrm{M}$ saccharose in a $1-\mathrm{mM}$ Tris- $\mathrm{HCl}$ buffer $(\mathrm{pH} 7.0$ ), $1 \mathrm{mM}$ EDTA, $1 \mathrm{mM}$ phenyl methyl sulfonyl fluoride and centrifuged at $12,000 \mathrm{~g}$ for $15 \mathrm{~min}$ to obtain a pellet containing nuclear, mitochondrial, and lysosomal fractions. All experiments were carried out at $4^{\circ} \mathrm{C}$. The supernate was transferred into microtubes $\left(\begin{array}{lll}170 & \mu l\end{array}\right)$ and centrifuged in a Beckman Airfuge (Beckman Instruments, Inc, Fullerton, Calif.) at $105,000 \mathrm{~g}$ for $10 \mathrm{~min}$ at $4^{\circ} \mathrm{C}$, to obtain a microsomal pellet. The $12,000 \mathrm{~g}$ and microsomal pellets were suspended, respectively, in 0.5 and $0.1 \mathrm{ml} 1 \%$ Triton X-100 and frozen and thawed three times. The enzymatic activity of these extracts was determined as described below and the protein concentration assayed according to Lowry et al. (13).

\section{Enzyme assays}

$\mathrm{NADH}$-cytochrome $b_{5}$ reductase is capable of reducing different types of electron acceptors: natural, seminatural, and artifical (xenobiotic) substrates. Therefore five types of assay were performed.

Assay 1. With soluble cytochrome $b_{5}$ as electron acceptor, assay 1 was prepared by trypsin digestion of rabbit liver microsomes according to Omura and Takesue (14). The technique used was that described by Leroux et al. (6). Due to pseudo first-order kinetics of the reaction, the velocity was defined by the apparent first-order rate constant $k$ per minute. Results were expressed as $k$ per milligram protein.

Assay 2. With the ferrocyanide-methemoglobin complex as electron acceptor, assay 2 was prepared as described by Hegesh et al. (15). The activity was expressed as micromoles or nanomoles of substrate reduced per minute and per milligram protein.

Assay 3. The NADH-diaphorase method of Scott and Mc Graw (16) using 2,6-dichlorophenol indophenol as final electron acceptor.

Assay 4. Another diaphorase assay in which the reduction of 2,6-dichlorophenol indophenol is coupled to that of 3-(4,5-dimethyl thiazolyl-2)-2,5-diphenyl tetrazolium bromide (MTT, Sigma Chemical Co.) (17).

Assay 5. This explored the NADH-ferricyanide reductase activity of the enzyme and was performed as described by Zamudio and Canessa (18).

Among these different methods that of Hegesh et al. (15), i.e. assay 2 , was the simplest and the most accurate, and therefore used in most of the experiments.

\section{Immunological methods}

Chicken anti-human erythrocyte cytochrome $b_{5}$ reductase was prepared as described previously (2). The $12,000-\mathrm{g}$ supernate of the C 252/B 95 control line prepared as described in procedure 1 was preincubated with increasing amounts of antibody. The incubation mixture was brought with saline up to a final volume of $80 \mu \mathrm{l}$ and left for $30 \mathrm{~min}$ at $4^{\circ} \mathrm{C}$. Then polyethylene glycol was added ( $5 \%$ final) and the mixture was incubated during $10 \mathrm{~min}$. The residual activity of the $30,000-g$ supernates was assayed according to the method of Hegesh et al. (15). The antiserum was titrated with a human erythrocyte cytochrome $b_{5}$ reductase crude preparation freed from hemoglobin by DEAE cellulose treatment $(2,6)$. Control experiments were performed using serum from a nonimmunized chicken.

\section{RESULTS}

\section{Cytochrome $b_{5}$ reductase activity in various human LCL}

Importance of the final electron acceptors. In order to study the specificity of the enzymatic activities of 
normal LCL, various substrates were tested such as: artifical electron acceptors (ferricyanide or 2,6-dichlorophenol indophenol or MTT-2,6-dichlorophenol indophenol), a seminatural substrate (the ferrocyanidemethemoglobin complex of Hegesh) or the natural substrate itself (cytochrome $b_{5}$ ). A detergent-treated total cell extract of the control C 252/B 95 line was used. Table I shows the results obtained with these different substrates: a methemoglobin reductase or cytochrome $b_{5}$ reductase activity is clearly present in normal LCL. The apparent Michaelis constant $\left(K_{\mathrm{m}}\right)$ for the methemoglobin ferrocyanide complex obtained according to Hanes' plot is $20 \mu \mathrm{M}$.

Influence of phase growth on enzymatic activity. Reproducible enzyme activity was found for a same cell line (C 252/B 95) at different intervals. The relation between enzymatic activity and phase growth has been studied. Throughout the different experiments, the presence of the enzyme was monitored by the ferrocyanide-methemoglobin reductase assay (assay 2). When cells were harvested after 1,3 , or $7 \mathrm{~d}$, the level of enzyme activity remained comparable (not shown).

Enzymatic activity in LCL of various origin. To determine whether the various LCL were relatively homogenous in their enzymatic expression, the ferrocyanide-methemoglobin reductase activity (assay 2) was measured in different lymphoid lines, six of them established from normal human B lymphocytes infected by EBV, five others derived from patients with nasopharyngeal carcinoma, and three others derived from Burkitt's lymphoma. Except for Daudi, the values obtained with these lines did not differ significantly from those repeatedly found with the control C 252/B 95 line (Table II).

Subcellular distribution of the enzyme. It has been shown that, according to its amphipathic nature (19),

TABLE I

Results Obtained with Different Final Electron Acceptors

\begin{tabular}{lc}
\hline \multicolumn{1}{c}{ Acceptor } & \multicolumn{1}{c}{ Activity } \\
\hline & Mean $\pm S D$ \\
Cytochrome $b_{5}$ & $6.53 \pm 0.05(5)$ \\
Ferrocyanide-methemoglobin complex & $0.057 \pm 0.019(13)$ \\
2,6-dichlorophenol indophenol & $0.034 \pm 0.008(5)$ \\
MTT-2,6-dichlorophenol indophenol & $0.077 \pm 0.007(5)$ \\
Ferricyanide & $0.343 \pm 0.095(5)$
\end{tabular}

Activity was determined in the total extracts (Methods, procedure 1) of control LCL (C 252/B 95), and expressed as micromoles substrate per minute per milligram protein with all the acceptors, with the exception of cytochrome $b_{5}$, for which the activity is expressed as first order rate constant (k) per milligram protein. MTT, 3-(4,5-dimethyl thiazolyl-2)2,5-diphenyl tetrazolium bromide.

The number of experiments is indicated between parentheses.
TABLE II

Ferrocyanide-Methemoglobin Reductase Activity of Different Lymphoid Cell Lines

\begin{tabular}{cc}
\hline \multicolumn{1}{c}{ Lymphoid cell lines } & Activity \\
\hline & $\begin{array}{c}\text { mnol/min/mg } \\
\text { protein }\end{array}$ \\
Established from cord lymphocytes & \\
infected by EBV & \\
- C 252/B 95 & $0.057 \pm 0.019(13)$ \\
- C 18/M 81 & 0.037 \\
- C 18/B 95 & 0.039 \\
- C 62/M 81 & 0.038 \\
- C 62/B 95 & 0.045 \\
- C 34/M 81 & 0.034 \\
Derived from patients with & \\
nasopharyngeal carcinoma & \\
- Ly 11 & 0.041 \\
26 & 0.033 \\
28 & 0.042 \\
64 & 0.048 \\
72 & 0.046 \\
Lymphoma lines & \\
- DAUDI & 0.021 \\
RA JI & 0.060 \\
\hline
\end{tabular}

Enzymatic activity was determined according to the method of Hegesh (15) in total extracts (Methods, procedure 1).

The number between parentheses refers to the number of experiments.

cytochrome $b_{5}$ reductase is bound to membranes such as microsomes (20), mitochondria (21), erythrocyte ghosts (22). It was also found as a free soluble form in the erythrocyte (3), in liver and placenta cytosol $(6,23)$. We estimated the distribution of the enzyme in the LCL. The ferrocyanide-methemoglobin reductase activity (assay 2) was determined in fractions obtained after homogeneization of the control cells (C 252/B 95) and centrifugation, as described in methods: $71 \%$ of the total enzymatic activity was found in the 12,000-g pellet, $16 \%$ in the $105,000-g$ microsomal pellet, and $7 \%$ in the cytosolic supernate (Table III).

Immunological studies. The immunological properties of the cytochrome $b_{5}$ reductase of lymphoid cells were compared to those of the erythrocyte enzyme. Fig. 1 shows the immunoinactivation curve obtained after incubation of a detergent-treated lymphoblast extract with different concentrations of an antiserum directed against human erythrocyte cytochrome $b_{5}$ reductase. The curve indicates that the cytochrome $b_{5}$ reductase of the LCL is inhibited by the antibody and therefore is immunologically related to the erythrocyte enzyme. However, the immunoinactivation curve slope of the lymphoblast cell extract is not identical to that of the erythrocyte enzyme. This 
TABLE III

Subcellular Distribution of Ferrocyanide-Methemoglobin Reductase of Normal LCL

\begin{tabular}{lcr}
\hline \multicolumn{1}{c}{ Subcellular fractions } & \multicolumn{2}{c}{ Total activity } \\
\hline & $\mu$ mol/min & $\%$ \\
Homogenate & 0.191 & 100 \\
$12,000 \mathrm{~g}$ pellet & 0.135 & 71 \\
$105,000 \mathrm{~g}$ microsomal pellet & 0.030 & 16 \\
$105,000 \mathrm{~g}$ cytosolic supernate & 0.013 & 7 \\
\hline
\end{tabular}

The ferrocyanide-methemoglobin reductase activity was measured according to the method of Hegesh (15) in the $12,000-g$ pellet, the $105,000-g$ pellet, and supernate of homogenized LCL (C 252/B 95).

The subcellular fractionation and extraction was performed as described in Methods (procedure 2).

may be due to a different accessibility for the antibody to the membrane bound enzyme of the lymphoid cells as compared to the soluble erythrocyte enzyme or to the difference in specific activity and in enzyme concentrations of the two preparations. Control serum of nonimmunized chicken had nearly no inhibitory effect. These results indicates the immunological relationship of the reductase from the LCL with the erythrocyte enzyme.

\section{Cytochrome $b_{5}$ reductase activity in LCL derived from subjects with congenital methemoglobinemia}

Enzyme activities in total extract of $L C L$ from patients with type I and type II RCM. The methemoglobin reductase and cytochrome $b_{5}$ reductase activities were determined in the lymphoblastoid cells derived from one subject with type I RCM (case REN) and from two subjects with type II RCM (cases BOU and BEN) and compared to the control line C 252/B 95 (Table IV). In the LCL from type I RCM, the methemoglobin reductase and cytochrome $b_{5}$ reductase activities represent, respectively, 49 and $53 \%$ of those from the controls. In the LCL from type II RCM, the enzymatic values were $5-9 \%$ of those from the control line. Therefore, a cytochrome $b_{5}$ reductase deficiency is clearly demonstrable in the LCL derived from patients with type I RCM. This deficiency is considerably more pronounced in the cells from the two patients with type II RCM. It is noteworthy that the values of methemoglobin reductase and of cytochrome $b_{5}$ reductase are in good agreement.

Comparison of the enzymatic activities of the $L C L$ with those of leukocytes and fibroblasts from patients with type I and type II RCM. Table IV compares the total activity obtained in LCL, leukocytes, and fibroblasts from patients with type I and type II RCM. In the

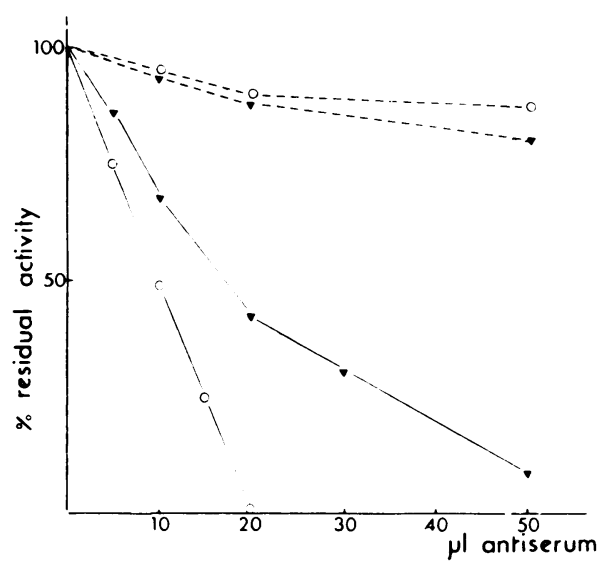

FigURE 1 Immunoinactivation of LCL enzyme by antiserum prepared against human erythrocyte cytochrome $b_{5}$ reductase. The results are expressed as percentage of the activity measured in control experiments according to the method of Hegesh (15). Chicken antiserum directed against human erythrocyte cytochrome $b_{5}$ reductase was preincubated with: $\bigcirc-0$, partially purified erythrocyte enzyme, $\boldsymbol{\nabla}-\boldsymbol{\nabla}$, $12,000-g$ supernate from normal lymphoblastoid cells (C 252/ B 95) extracted with $1 \%$ Triton X-100. Normal chicken serum was incubated with identical preparations (dotted lines). Other conditions are described in Methods.

LCL from a patient (REN) with type I RCM, the level of methemoglobin reductase $(28 \mathrm{nmol} / \mathrm{min}$ per $\mathrm{mg}$ protein) was found lower than that of the control value of LCL $(57 \pm 19 \mathrm{nmol} / \mathrm{min}$ per $\mathrm{mg}$ protein). However, in the leukocytes of this patient, the methemoglobin reductase level was subnormal $(54 \mathrm{nmol} / \mathrm{min}$ per $\mathrm{mg}$ protein) as compared to the control value of methemoglobin reductase of leukocytes $(70 \pm 20 \mathrm{nmol} / \mathrm{min}$ per $\mathrm{mg}$ protein). Therefore, the enzymatic defect of type I RCM was more expressed in the lymphoid cells as compared to the other cells. In type II RCM (BOU and BEN), the enzyme deficiency was major in the three types of cells, regardless of the substrate used. However, the defect was less pronounced in the LCL than in leukocytes and fibroblasts and some cytochrome $b_{5}$ reductase activity was detectable in the LCL from the type II RCM (Table IV).

Subcellular distribution of the residual enzyme activity. As recently reported (21), the molecular identity of microsomal and mitochondrial cytochrome $b_{5}$ reductase of rat liver has been established on enzymatic and immunochemical grounds. The study of the subcellular distribution of the residual enzyme activity of LCL from type I and type II RCM may provide a genetic verification of this hypothesis. The methemoglobin reductase activity was determined in the different fractions: $12,000-g$ pellet, 105,000-g pellet and supernate of the homogenized LCL. In the LCL from type I RCM (REN) and from type II RCM (BEN and BOU), the enzymatic defect is clearly expressed (Table 
TABLE IV

Enzymatic Activities in Lymphoblastoid Cells Compared with Those of Leukocytes and Fibroblasts from Patients with Type I and Type II RCM and from Control Subjects

\begin{tabular}{|c|c|c|c|c|c|c|c|}
\hline & & \multicolumn{6}{|c|}{ Specific activity } \\
\hline & & \multicolumn{3}{|c|}{$\begin{array}{l}\text { Methemoglobin reductase } \\
\text { nmol/min/mg }\end{array}$} & \multicolumn{3}{|c|}{$\begin{array}{l}\text { Cytochrome } b_{3} \text { reductase } \\
\qquad / \mathrm{mg}^{*}\end{array}$} \\
\hline & & LCL & Leukocytes & Fibroblasts & LCL & Leukocytes & Fibroblasts \\
\hline Control & & 57.4 & 70.1 & 70 & 6.5 & 3.2 & 4.0 \\
\hline REN & Type I RCM & 28.2 & 54.3 & ND & 3.4 & ND & ND \\
\hline BOU & Type II RCM & 3.5 & 1.0 & 1.5 & 0.3 & 0 & 0 \\
\hline $\mathrm{BEN}$ & Type II RCM & 5.1 & 2.5 & 3.4 & 0.5 & 0 & 0 \\
\hline
\end{tabular}

The ferrocyanide-methemoglobin reductase (15) and cytochrome $b_{5}$ reductase (6) activities were measured in the total extracts prepared as described under material and methods (procedure 1).

Control LCL: C252/B95.

* Activity expressed as first order rate (k) per milligram protein.

$\mathrm{V})$ in the three subcellular fractions investigated (12,000-g pellet, 105,000-g pellet, and supernate), as compared to the values obtained with the control LCL (C 252/B 95). The lower enzymatic activity found in the total extracts of the LCL of the type II RCM (Table IV) seems to be essentially due to a decrease of activity in the 12,000-g pellet fraction of these cells (Table V).

\section{DISCUSSION}

$\mathrm{NADH}$-cytochrome $b_{5}$ reductase (EC 1.6.2.2.) is an amphipathic protein that is tightly bound to different membrane systems such as endoplasmic reticulum, mitochondria, and erythrocyte ghosts (19-22). It is monomeric and is encoded by a single locus-DIA ${ }_{1}^{-}$ assigned to chromosome $22(9,10)$. In the erythrocyte it has been shown that the enzyme that acts as

\section{TABLE V}

Subcellular Distribution of the Residual Methemoglobin Reductase Activity of Lymphoblastoid Cell Lines Derived from Subjects with Type I and Type II RCM

\begin{tabular}{llrrr}
\hline & & \multicolumn{3}{c}{$\begin{array}{c}\text { Specific activity } \\
\text { nmol/min/mg protein }\end{array}$} \\
\cline { 3 - 5 } Cell lines & \multicolumn{1}{c}{ Origin } & $\begin{array}{c}12,000 \mathrm{~g} \\
\text { pellet }\end{array}$ & $\begin{array}{c}105,000 \mathrm{~g} \\
\text { pellet }\end{array}$ & $\begin{array}{c}105,000 \mathrm{~g} \\
\text { supernate }\end{array}$ \\
\hline C 252/B 95 & Control & 82.0 & 46.7 & 3.7 \\
REN & Type I RCM & 26.5 & 7.2 & 1.7 \\
BEN & Type II RCM & 6.4 & 9.3 & 1.6 \\
BOU & Type II RCM & 2.8 & 10.5 & 2.6 \\
\hline
\end{tabular}

The enzyme activity was assayed by the method of Hegesh et al. (15) in fractions obtained as described in Methods (procedure 2).

Full extraction of the $12,000 \mathrm{~g}$ and $105,000 \mathrm{~g}$ pellets was ensured by Triton X-100 (1\%). a methemoglobin reductase, the so-called NADHdiaphorase (16), is actually a soluble form of NADHcytochrome $b_{5}$ reductase (3-6). This form most probably derives from the membrane-bound enzyme by partial proteolysis and removal of the C-terminal hydrophobic segment $(3,19,22-24)$.

RCM is due to a defect of this enzyme. In our laboratory 23 cases of RCM have been observed in the past 10 years. 14 individuals exhibited a benign clinical pattern, in which the only symptom was cyanosis due to methemoglobinemia. The level of methemoglobin was easily controlled by methylene blue, ascorbic acid, or riboflavin $(25,26)$. In this well-tolerated disease we found that the enzyme defect was expressed in the erythrocytes, whereas the leukocytes of these patients exhibited either normal or subnormal levels. We called it type I RCM (7). In contrast, nine patients exhibited a completely different picture in which methemoglobinemia was associated with severe mental retardation and early neurologic abnormalities with bilateral athetosis (7). Control of methemoglobinemia was without effect on the clinical course. In this lethal disease, the enzyme defect was fully expressed not only in the erythrocytes but also in leukocytes, fibroblasts, liver, muscle, and brain $(7,8,27)$. This indicates that the severe form of RCM is a systemic disease due to generalized deficiency of cytochrome $b_{5}$ reductase. We called this form type II RCM (7). On these grounds, prenatal diagnosis was successfully performed by analyzing the cytochrome $b_{5}$ reductase of cultured amniotic cells from two fetuses at risk for the type II deficiency (28). Different mutations at the DIA locus might account for the two forms. However, at the present time, there is no explanation at the molecular level for this phenotypic heterogeneity. One of the reasons for our lack of knowledge in this respect is the scarcity of the material available from patients with RCM. In the erythrocytes, the usual source of enzyme, the residual activity 
is very low and extremely unstable, especially in the type II form (27 and unpublished observations). Fibroblasts were cultured from skin biopsy specimens obtained in some of our patients with RCM $(7,8)$. However, this material was still not enough to permit a comparative study of the type I and the type II defects. We therefore decided to establish stable LCL from these patients by EBV transformation of their peripheral lymphocytes. The advantages of such lines are well known: rapid and easy growth in suspension yielding considerable amount of cellular material, indefinite life in vitro of cells retaining their original phenotype and genotype over long periods in culture (29). These cells have been used successfully for genetic studies of human defects $(29,30)$.

To ascertain the usefulness of this material for studying both types of RCM, it was necessary to estimate and characterize the cytochrome $b_{5}$ reductase of LCL derived from nondeficient subjects. In six different lines established by in vitro EBV infection, in five spontaneous lines derived from nasopharyngeal carcinoma and in three spontaneous lines derived from Burkitt's tumors, the enzyme activity was found to be similar. We also checked that the enzyme activity did not vary and was independent of the growth characteristics of the cells at the time of harvesting $(1,3$, or $7 \mathrm{~d}$ of culture). On the other hand, neither the presence of the EBV genome nor the malignant origin of some cells did affect the cytochrome $b_{5}$ reductase expression of the LCL (Table II). However, one exception was the Daudi cell line in which only half of the "normal" cytochrome $b_{5}$ reductase activity was found. This is reminiscent of the partial defect of $\mathrm{N}$-acetyl hexosaminidase observed in the same cell line (31). In our study we also established, as a preliminary, that the cytochrome $b_{5}$ reductase of the LCL is immunologically related to the erythrocyte enzyme. Its subcellular distribution, investigated in one of the control LCL (C 252/B 95), showed that the enzyme is present in the mitochondrial, the microsomal, and the cytosolic fractions. This is consistent with the recently reported existence of cytochrome $b_{5}$ reductase in the mitochondrial (21) and cytosolic (23) fractions of liver. It should be noted that $\sim 90 \%$ of the enzymatic activity of the LCL is bound to the subcellular organelles. This binding requires the use of a detergent to unmask the hidden amphipathic enzyme $(19,22)$.

Altogether these results indicate that LCL established from deficient patients should be suitable for studying the two types of RCM. Using natural (cytochrome $b_{5}$ ) and seminatural (ferrocyanide-methemoglobin complex) substrates, we demonstrated the existence of a partial defect of cytochrome $b_{5}$ reductase in the LCL from a patient with type I RCM (case REN), and a more pronounced defect in the cells derived from two patients with type II RCM (cases BOU and BEN). In both types of cells the enzyme deficiency predominated in the mitochondrial and microsomal fractions, the deficiency being more important in the type II cells. These results confirm that all the subcellular forms of cytochrome $b_{5}$ reductase are under the control of a single gene: the DIA $\mathrm{A}_{1}$ locus.

The enzymatic defect observed in LCL correlates with the activities measured in a mixed population of circulating leukocytes from patients with both types of RCM (Table IV). However, in type I RCM, the enzyme activity was significantly lower in LCL than in leukocytes. We have no explanation for this phenomenon, which could be accounted for by either differential stability of the DIA 1 product, or by differential expression of the diaphorase isozymes (32). In the LCL from type II RCM, the enzyme defect was much more pronounced than in type I cells (Table IV), as already found with other nucleated cells $(7,8,27,28)$. Of special interest is the fact that the LCL from type II RCM, in contrast to leukocytes and fibroblasts, expressed some residual activity that can be useful to further characterize the mutated reductase. The lines derived from patients with type I and type II RCM should prove useful as a model for investigating, at cellular and molecular levels, the biological consequences of defects involving the cytochrome $b_{5}$ reductase gene.

\section{ACKNOWLEDGMENTS}

F. Carrouget is thanked for typing the manuscript. Dr. Aléna Leroux is gratefully acknowledged for providing antiNADH methemoglobin reductase antiserum and for measuring enzymatic activities in leukocytes and fibroblasts. We thank Professor Khati, Hospital Mustapha, Algiers, and Dr. Bakouri, Hospital Beni-Messous, Algiers, for providing samples of methemoglobinemic subjects.

This work was supported in part by a grant from the University René Descartes of Paris (Paris V).

\section{REFERENCES}

1. Scott, E. M., and I. V. Griffith. 1959. The enzymatic defect in hereditary methemoglobinemia:diaphorase. Biochim. Biophys. Acta. 34: 584-586.

2. Leroux, A., and J. C. Kaplan. 1972. Presence of red cell type NADH-methemoglobin reductase (NADH-diaphorase) in human non erythroid cells. Biochem. Biophys. Res. Commun. 49: 945-950.

3. Hultquist, D. E., and P. G. Passon. 1971. Catalysis of methaemoglobin reduction by erythrocyte cytochrome $b_{5}$ and cytochrome $b_{5}$ reductase Nature (Lond.) 229: $252-254$.

4. Kuma, F., R. A. Prough, and B. S. S. Masters. 1976. Studies on methemoglobin reductase. Immunochemical similarity of soluble methemoglobin reductase and cytochrome $b_{5}$ of human erythrocytes with NADH-cytochrome $b_{5}$ reductase and cytochrome $b_{5}$ of rat liver microsomes. Arch. Biochem. Biophys. 172: 600-607.

5. Goto-Tamura, R., Y. Takesue, and S. Takesue. 1976. Immunological similarity between NADH-cytochrome $b_{5}$ reductase of erythrocytes and liver microsomes. Biochim. Biophys. Acta. 423: 293-302. 
6. Leroux, A., L. Torlinski, and J. C. Kaplan. 1977. Soluble and microsomal form of NADH-cytochrome $b_{5}$ reductase from human placenta. Similarity with NADH-methemoglobin reductase from human erythrocytes. Biochim. Biophys. Acta. 481: 50-62.

7. Kaplan, J. C., A. Leroux, and P. Beauvais. 1979. Formes cliniques et biologiques du déficit en cytochrome $b_{5}$ réductase. C. R. Soc. Biol. 173: 368-379.

8. Leroux, A., C. Junien, J. C. Kaplan, and J. Bamberger. 1975. Generalized deficiency of cytochrome $b_{5}$ reductase in congenital methaemoglobinaemia with mental retardation. Nature (Lond.). 258: 619-620.

9. Fisher, R. A., S. Povey, M. Bobrow, E. Solomon, Y. Boyd, and B. Carritt. 1977. Assignment of the DIA locus to chromosome 22. Ann. Hum. Genet. 41: 151-155.

10. Junien, C., M. Vibert, D. Weil, Nguyen Van Cong, and J. C. Kaplan. 1978. Assignment of NADH-cytochrome $b_{5}$ reductase ( $\mathrm{Dia}_{1}$ locus) to human chromosome 22. Hum. Genet. 42: 233-239.

11. Yata, J., C. Desgranges, T. Nakagawa, M. C. Favre, and G. De Thé. 1975. Lymphoblastoid transformation and kinetics of appearance of viral nuclear antigen (EBNA) in cord-blood lymphocytes infected by Epstein-Barr virus (EBV). Int. J. Cancer. 15: 377-384.

12. De Thé, G., H. C. Ho, H. C. Kwan, C. Desgranges, and M. C. Favre. 1970. Nasopharyngeal carcinoma (NPC). ITypes of cultures derived from tumour biopsies and nontumorous tissues of Chinese patients with special reference to lymphoblastoid transformation. Int. J. Cancer. 6: $189-206$.

13. Lowry, O. H., N. Y. Rosebrough, A. L. Farr, and R. J. Randall. 1951. Protein measurement with the Folin phenol reagent. J. Biol. Chem. 193: 265-275.

14. Omura, T., and S. Takesue. 1970. A new method for simultaneous purification of cytochrome $b_{5}$ and NADPHcytochrome $c$ reductase from rat liver microsomes. J. Biochem. (Tokyo). 67: 249-257.

15. Hegesh, E., N. Calmanovici, and M. Avron. 1968. New method for determining ferrihemoglobin reductase (NADH-methemoglobin reductase) in erythrocytes. $J$. Lab. Clin. Med. 72: 339-344.

16. Scott, E. M., and J. C. McGraw. 1962. Purification and properties of diphosphopyridine nucleotide diaphorase of human erythrocytes. J. Biol. Chem. 237: 249-252.

17. Choury, D., and J. C. Kaplan. 1980. Diaphorase P: A new foetal isozyme identified in human placenta. Biochim. Biophys. Acta. 613: 18-25.

18. Zamudio, I., and M. Canessa. 1966. NADH-dehydrogenase activity of human erythrocyte membranes. Biochim. Biophys. Acta. 120: 165-169.

19. Spatz, L., and P. Strittmatter. 1973. A form of reduced nicotinamide adenine dinucleotide cytochrome $b_{5}$ reductase containing both the catalytic site and an additional hydrophobic membrane-binding segment. J. Biol. Chem. 248: 793-799.
20. Strittmatter, P., and S. F. Velick. 1957. The purification and properties of microsomal cytochrome $b_{5}$ reductase. J. Biol. Chem. 228: 785-799.

21. Kuwahara, S., Y. Okada, and T. Omura. 1978. Evidence for molecular identity of microsomal and mitochondrial NADH-cytochrome $b_{5}$ reductases of rat liver. J. Biochem. (Tokyo). 83: 1049-1059.

22. Choury, D., A. Leroux, and J. C. Kaplan. 1981. Membrane-bound cytochrome $b_{5}$ reductase (methemoglobin reductase) in human erythrocytes. Study in normal and methemoglobinemic subjects. J. Clin. Invest. 67: 149-155.

23. Lostanlen, D., A. Vieira De Barros, A. Leroux, and J. C. Kaplan. 1978. Soluble NADH-cytochrome $b_{5}$ reductase from rabbit liver cytosol: partial purification and characterization. Biochim. Biophys. Acta. 526: 42-51.

24. Mihara, K., R. Sato, R. Sakakibara, and.H. Wada. 1978. Reduced nicotinamide adenine dinucleotide-cytochrome $b_{5}$ reductase: location of the hydrophobic, membranebinding region at the carboxyl-terminal end and the masked amino terminus. Biochemistry. 17: 2829-2834.

25. Kaplan, J. C., and M. Chirouze. 1978. Therapy of recessive congenital methaemoglobinaemia by oral riboflavine. Lancet. II: 1043-1044.

26. Schwartz, J. M., and E. R. Jaffé. 1978. Hereditary methemoglobinemia with deficiency of NADH-dehydrogenase. In The Metabolic Basis of Inherited Disease. J. B. Stanbury, J. B. Wyngaarden, D. S. Fredrickson, editors. McGraw Hill Inc., New York. 1452-1464.

27. Kaplan, J. C., A. Leroux, S. Bakouri, J. P. Grangaud, and 11. Benabadji. 1974. Le lésion enzymatique dans la méthémoglobinémie congénitale récessive avec encéphalopathie. N. Rev. Fr. Hématol. 14: 755-770.

28. Junien, C., A. Leroux, D. Lostanlen, A. Reghis, J. Boué, H. Nicolas, A. Boué, and J. C. Kaplan. 1981. Antenatal diagnosis of congenital enzymopenic methaemoglobinaemia with mental retardation due to generalized cytochrome $b_{5}$ reductase deficiency. Prenatal Diagnosis. 1: 17-24.

29. Povey, S., S. E. Gardiner, B., S. Mowbray, H. Harris, E. Arthur, C. M. Steel, C. Blenkinsop, and H. J. Evans. 1973. Genetic studies on human lymphocytoid lines: isozyme analysis on cell lines from 41 different individuals and on mutants produced following exposure to a chemical mutagen. Ann. Hum. Genet. 36: 247-266.

30. Glade, P. R., and N. G. Beratis. 1975. Long term lymphoid cell lines in the study of human genetics. Prog. Med. Genet. 1: 1-48.

31. Swallow, D. M., S. E. Gardiner, H. Harris, E. Arthur, C. M. Steel, and H. J. Evans. 1977. Lysosomal enzymes in human lymphoblastoid lines: unusual characteristics of Raji and Daudi. Ann. Hum. Genet. 41: 9-16.

32. Fisher, R. A., Y. H. Edwards, W. Pritt, J. Potter, and D. A. Hopkinson. 1977. An interpretation of human diaphorase isozymes in terms of three gene loci DIA 1, DIA 2 and DIA 3. Ann. Hum. Genet. 41: 139-149. 